Article

\title{
Overcoming Barriers to Livability for All Ages: Inclusivity Is the Key
}

\author{
Xue Zhang ${ }^{1, *}$, Mildred E. Warner ${ }^{2}$ and Stephanie Firestone ${ }^{3}$ \\ ${ }^{1}$ Regional Science, Cornell University, Ithaca, NY 14850, USA; E-Mail: xz435@cornell.edu \\ ${ }^{2}$ City and Regional Planning, Cornell University, Ithaca, NY 14850, USA; E-Mail: mwarner@cornell.edu \\ 3 Policy, Research, and International-PRI, AARP, Washington, DC 20049, USA; E-Mail: sfirestone@aarp.org \\ * Corresponding author
}

Submitted: 14 December 2018 | Accepted: 18 February 2019 | Published: 18 June 2019

\begin{abstract}
The rapid pace of population aging in cities around the world demands that planners design communities that are livable for people of all ages and abilities. In 2017, to assess progress toward this end, AARP and the International Division of the American Planning Association conducted a global survey of planners on their efforts to incorporate a livable-communityfor-all-ages approach into their work. The survey of 559 planners measured motivators, barriers, strategies for engagement and practices facilitating planners' work on livable communities for all ages (LCA). Using the international survey, we analyze factors driving local governments' actions to advance LCA, and factors driving outcomes incorporating a livablecommunity-for-all-ages approach in planning practices. We show how these differ between the US and non-US respondents, including how US suburbs and rural areas lag in actions toward LCA. Regression results show that local motivations such as awareness of substantial growth in older populations is a primary factor motivating local governments to take more actions. While physical design is a critical part of the solution, we find that facilitating practices and community engagement in the process are key to advancing planning for age-friendly communities. Additionally, communities that practice more traditional approaches to planning and have limited resources actually exhibit a higher level of LCA outcomes. This suggests that focusing on community engagement and facilitating practices could be a promising approach to incorporating an all age lens in planning practices.
\end{abstract}

\section{Keywords}

age-friendly community; aging; government; inclusive engagement; livability; planning

\section{Issue}

This article is part of the issue "The City, Aging and Urban Planning", edited by Matthias Drilling (University of Applied Sciences and Arts Northwestern Switzerland) and Fabian Neuhaus (University of Calgary, Canada).

(C) 2019 by the authors; licensee Cogitatio (Lisbon, Portugal). This article is licensed under a Creative Commons Attribution 4.0 International License (CC BY).

\section{Introduction}

The world population is rapidly getting older because of lower fertility rates and longer lifespans. The population aged 65 and over will double from 2025 to 2050 (He, Goodkind, \& Kowal, 2016). The increase in older populations in towns, suburbs and cities around the world highlights the need to make communities livable for people of all ages and abilities. A livable-community-for-allages approach involves planning to help "communities ensure appropriate physical infrastructures (e.g., housing, transportation, built environment, access to healthy foods) and social infrastructures (e.g., health care, support services, engagement opportunities) for residents throughout an expanding life course" (Firestone, Keyes, \& Greenhouse, 2018, p. 20). The idea behind a livablecommunity-for-all-ages approach has been spearheaded by the World Health Organization (WHO), the United Nations Children's Fund (UNICEF) and, in the US, by AARP and the American Planning Association (APA). The first guidance in this space, the WHO's guide to building global age-friendly cities, recognized the importance of optimizing the opportunity for health, participation, and security to increase the quality of life for older adults 
(WHO, 2002, 2007). In 2005, AARP's report Livable Communities: Creating Environments for Aging emphasized the importance of affordable housing, supportive community services, and convenient mobility to meet the needs of older adults (Kochera, Straight, \& Guterbock, 2005). UNICEF's 2004 and its most recent 2018 guide for child-friendly cities also emphasized actions consistent with a livable-community-for-all-ages approach. All three entities continue to refine and promulgate their guidance.

Local governments are engaging in designing programs and service delivery in response to the needs of older adults (Farber, Shinkle, Lynott, Fox-Grage, \& Harrell, 2011; Lehning, 2012). Planning and design play an important role in decreasing the barriers often posed by zoning and increasing residents' accessibility to community services (Firestone et al., 2018; Warner, Xu, \& Morken, 2017). The APA's Aging in Community Policy Guide encourages planning approaches to land use, housing, transportation, and social services that comprehensively enhance the well-being of residents across the lifecycle (APA, 2014).

In this article we explore the factors that lead planners to advance actions toward livable communities for all ages (LCA) and the factors driving the outcomes of incorporating a livable-community-for-all-ages approach in planning practices at the local government level. Using an international survey of planners conducted in 2017, we are able to differentiate actions and outcomes between the US respondents and those in other countries around the world. Our survey results highlight the social layer-engagement and facilitating practices-in helping communities become more age-friendly.

\section{Literature Review}

Local governments play an important role in building age-friendly communities (Lui, Everingham, Warburton, Cuthill, \& Bartlett, 2009). The WHO Global Network of Age-Friendly Cities and Communities ${ }^{1}$ has over 500 members in 37 countries. The AARP Network of Age-Friendly States and Communities has more than 310 community and three state members. Although age-friendly cities focus on developing supportive services for older adults, WHO's eight domains of age-friendly communities overlap with the characteristics of UNICEF's childfriendly cities, such as health services, safe outdoor spaces, participation and social inclusion (UNICEF, 2004; WHO, 2007). Age-friendly initiatives recognize the possibility of implementing multigenerational approaches that can facilitate greater functional capacity for people from early life to older age (Buffel \& Phillipson, 2016; Fitzgerald \& Caro, 2014; Warner \& Homsy, 2017; Warner, $\mathrm{Xu}, \&$ Morken, 2017). A multigenerational approach requires attention to physical design, services (both formal and informal), cross-agency collaboration and participation of families with children and older adults in en- suring community planning to meet their needs (Choi \& Warner, 2015; Severcan, 2015a; Warner, 2017; Warner \& Zhang, 2019).

According to a 2018 AARP survey of home and community preferences, while $76 \%$ of Americans aged 50 and older say they prefer to remain in their current residence and $77 \%$ would like to live in their community as long as possible, just $59 \%$ anticipate they will be able to stay in their community, either in their current home $(46 \%)$ or a different home within their community $(13 \%$; AARP, 2018). This significant gap requires government interventions around land use, transportation, and housing (Ball, 2004; Farber et al., 2011; Lehning, 2012; Winick \& Jaffe, 2015). Lehning (2014) finds that most local and regional governments in age-friendly communities in the San Francisco Bay Area use more incentives for mixed use neighborhoods and public transportation. Numerous studies have emphasized the importance of collaboration between local governments and other entities, such as federal government, business, and non-profit organizations in building age-friendly communities (Glicksman, Clark, Kleban, Ring, \& Hoffman, 2014; Greenfield, Oberlink, Scharlach, Neal, \& Stafford, 2015).

Strategic and land use planning creates the leverage points to build age-friendly communities. Based on a US national survey on health-related services in 2010, Warner, Xu and Morken (2017) found that planning is the key to increase health-related services for older adults, even in rural areas lagging in community services. Winters et al. (2015) surveyed older adults living in downtown Vancouver, Canada and found walkable neighborhood planning and design are key to increasing older adults' mobility and supporting them to "age in place". Survey responses from members of the European Healthy City Network also show that integrating age-friendly strategies in planning could improve the independence of older adults and increase their contribution to the social and economic development of cities (Green, 2013). A recent special issue of the Italian planning journal iQuaderni di Urbanistica Tre (Andriola \& Muccitelli, 2017) emphasizes the importance of services, public space, mobility and participation at the neighborhood scale. Severcan (2015a, 2015b) has given specific emphasis to strategies to engage children and how these can increase sense of place in both rural and urban contexts in Turkey (Sancar \& Severcan, 2010).

Building age-friendly communities is challenging. Lehning and Greenfield (2017) summarize recent studies on age-friendly initiatives, and indicate three barriers: lack of knowledge, funding, and practical guidance. Emlet and Moceri (2012) examine over 5000 young adults and older adults' opinions on age-friendly communities in the US and find that lack of interactions with organizations and accessible transportation are primary barriers to building social connections in age-friendly communities. Also, a study on age-friendly communities in Canada indicates that accessibility, transportation, in-

\footnotetext{
${ }^{1}$ For more information see: who.int/ageing/age-friendly-environments
} 
formation and affordability are factors affecting people's ability to age in place (Novek \& Menec, 2014). Kendig, Elias, Matwijiw and Anstey (2014) assess age friendly initiatives in Australia and argue that governments' efforts on building age-friendly communities are restricted by political uncertainty and fiscal stress. Pratt and Warner (2018) examine rural communities in Ecuador and find that investments in public infrastructure enhance families' well-being, but lack of political voice and access to finance limits the potential for active citizenship. Improving engagement and civic participation, which is the main factor cited in all guidelines for building age-friendly communities (APA, 2014; Lui et al., 2009; UNICEF, 2018; WHO, 2007), could help address these barriers. Engagement could help increase social capital and inclusion (Buffel \& Phillipson, 2016; Greenfield et al., 2015; Lehning, 2014), and community services (Warner, Homsy, \& Morken, 2017; Warner, Xu, \& Morken, 2017). Based on a national survey of 1500 US communities in 2010, Warner, Homsy and Morken (2017) found that public planning and engagement of seniors in the planning process helps private entrepreneurs see new market possibilities in serving the needs of older adults.

Currently, age-friendly planning and design are decidedly urban-focused. Suburban and rural communities lag in age-friendly built environment and services around the world (Fitzgerald \& Caro, 2014; Glasgow \& Brown, 2012; WHO, 2007). The US suburb, which was designed after World War II for young families with children, is both aging (Lee, Hong, \& Park, 2017) and becoming more ethnically diverse among younger families (Micklow \& Warner, 2014). Traditional suburban design needs to transform to better meet the needs of young families and older adults. However, the built environment in older suburbs does not match the needs of older adults in terms of housing and transportation (Hanlon, 2008; Lee et al., 2017). Young and Keil (2014) study the interaction between urban and suburban in Canada and find that lack of public transportation and housing affordability are the main infrastructure challenges in the inner ring suburbs. Canada has a large proportion of seniors living in rural areas (Plouffe \& Kalache, 2011), but less attention has been paid to building age-friendly rural communities (Lui et al., 2009). In the US, nonmetropolitan areas have a higher percentage of older adults (18\%) than metropolitan areas (14\%) according to the five-year American Community Survey estimates of 2012-2016 (US Census Bureau, 2017). Low density suburban and rural areas have the fastest growth rate of older adults (Joint Center for Housing Studies, 2018), but those areas often cannot follow urban-biased design guidelines based on New Urbanist principles of density, walkability, and mixed-use (Duany \& Plater-Zyberk, 2009; Howe, 2012). Also, suburban and rural communities usually provide lower levels of services (Warner, 2006), especially for older adults (Brown, Glasgow, Kulcsar, Sanders, \& Thiede, 2018; Morken \& Warner, 2012; Thiede, Brown, Sanders, Glasgow, \& Kulcsar, 2017; Warner \& Morken,
2013). In 2006, the group of Federal, Provincial and Territorial Ministers Responsible for Seniors in Canada published Age-Friendly Rural and Remote Communities: A Guide, which discusses the eight domains of WHO's age-friendly city from the rural perspective (Gallagher, Menec, \& Keefe, 2006). The guide recognizes the diversity of rural areas and the importance of collaboration and partnerships.

Most research focuses on approaches to building agefriendly communities but omits factors driving actions by local governments and planners, the barriers to implementing age-friendly approaches, and the evaluation of outcomes. A recent US study, based on a nationwide survey, finds participation, planning and zoning are key to ensuring better built environment outcomes for both children and older adults, even in suburban and rural areas (Warner \& Zhang, 2019). Lui et al. (2009) review the international journals on age-friendly communities from 2005 to 2008 and identify three gaps in the literature: urban-biased research which lacks study of rural areas, the balance between improving social inclusion and protecting individual diversity, and the evaluation of age-friendly approaches and outcomes. This article addresses the first and third gaps. We examine the differences among urban, suburban, and rural local government actions, and the incorporation of age-friendly considerations in planning practices.

\section{Data}

Study data were obtained from the 2017 International Planner Engagement Survey on LCA. In this survey LCA are defined as:

Communities that are intentional about being great places for people to grow up AND grow old, by ensuring appropriate physical infrastructures (housing, transportation, built environment, access to healthy foods) and social infrastructures (i.e., health care, support services, engagement opportunities) for residents throughout an expanding life course. Sometimes LCA is referred to by other names such as Agefriendly Communities or Lifelong Communities.

The survey was conducted by AARP, the APA International Division, Cornell University and Arup International consulting firm. The survey was distributed through partner organizations and professional networks of planners and reached planners from 33 countries. We received responses from 559 planners of which $72 \%$ were from the US and $28 \%$ were from other countries $19 \%$ from Australia and New Zealand, 9\% from Europe, 6\% from Canada, and 4\% from the Global South: Latin America, Asia, Africa, and the Middle East). Survey respondents from the US represent smaller communities and more suburbs compared to other countries. The majority of survey respondents are from the public sector and have worked as planners for five to twenty years. We separate 
the sample into a US subsample and non-US subsample due to the large number of responses from the US.

The US survey respondents reported their local governments took fewer actions to advance LCA (variable "LCA actions") and had a lower extent of LCA incorporation (variable "LCA outcomes") than planners from the non-US sample (Table 1). LCA actions and outcomes are separated based on factor analysis. LCA outcomes are measured by the extent of incorporation of LCA considerations in eleven planning areas on a scale from 1 ("not at all") to 5 ("a great extent"). The eleven planning areas were: community planning, parks and public spaces, community and health services, and civic engagement/participation, land-use planning/zoning, economic development, housing, transportation, buildings and public facilities, resilience, access to healthy food and physical activity.

We combined all the elements to create an outcome indicator (alpha 0.9). More than $50 \%$ of US respondents reported that LCA was incorporated into each planning practice at the median extent (median score $=3$ ). More than $50 \%$ of planners from other countries indicated that the LCA approach was incorporated in the areas of community planning, parks and public spaces, community and health services, and civic engagement at a larger extent (median score $=4$ ), and the incorporation of the LCA approach in other planning practices at the median level (median score $=3$ ). Thus, the non-US respondents report a higher level of LCA outcomes.

LCA actions are measured by the total number of local government actions to advance LCA (Table 1, alpha 0.8 ). The most common actions are walkability and accessibility assessment (38\%) and including the LCA approach in land use and transportation plans (33\%). The non-US sample has a higher level of LCA actions. The adoption of a policy to improve aging residents' quality of life is the main LCA action in non-US countries (32\%), compared to the US (19\%). Local governments in other countries are more likely to use financial resources (25\%) and outreach events (20\%) to support LCA than the US local governments ( $12 \%$ financial resources and $13 \%$ outreach events). Only $8 \%$ of planners reported that local governments signed on to a formal LCA program, but the number is significantly higher in the non-US sample (nonUS sample: $12 \%$ compared to US sample: $6 \%$ ). There is not a significant difference between US and other countries in auditing the impact of community programs and services on older adults (17\%), or in developing a citizen advisory or steering committee for LCA (14\%).

\section{Model}

We test two dependent variables-LCA actions and LCA outcomes. Our independent variables are motivations,

Table 1. Dependent variables. Source: International Planner Engagement Survey (AARP, 2017).

LCA outcomes: The extent an all ages lens has been incorporated into your planning practice, scale from 1 (not at all) to 5 (a great extent). Median values overall are shown below.

- Community planning (4)

- Parks \& public spaces (4)

- Community \& health services (3)

- Civic engagement/participation (3)

- Land-use planning/zoning (3)

- Economic development (3)

- Housing (3)

-Transportation (3)

- Buildings \& public facilities (3)

- Resilience (3)

- Access to healthy food and physical activity (3)

LCA actions: Local governments actions to advance LCA (\% yes overall)

- Performed a walkability/accessibility assessment (38\%)

- Incorporated LCA considerations in comprehensive land use/long term transportation or other major plan (33\%)

- Adopted an actual policy that directly improves the quality of life for aging residents (22\%)

- Audited community programs and services for their impact on older adults (17\%)

- Allocated financial resources to support the development of LCA (15\%)

- Hosted LCA outreach events (15\%)

- Developed a citizen advisory or steering committee for LCA (14\%)

- Signed on to a formal LCA program, such as WHO Global Network of Age-friendly Cities and Communities, or joined a national or regional network (8\%)

\begin{tabular}{cc} 
US & Non-US \\
\hline 3 & 4 \\
3 & 4 \\
3 & 4 \\
3 & 4 \\
3 & 3 \\
3 & 3 \\
3 & 3 \\
3 & 3 \\
3 & 3 \\
3 & 3 \\
3 & 3 \\
\hline US & Non-US \\
\hline $39 \%$ & $35 \%$ \\
$31 \%$ & $36 \%$ \\
& \\
$19 \%$ & $32 \%$ \\
$16 \%$ & $20 \%$ \\
$12 \%$ & $\mathbf{2 5 \%}$ \\
$\mathbf{1 3 \%}$ & $\mathbf{2 0 \%}$ \\
$12 \%$ & $18 \%$ \\
$6 \%$ & $12 \%$ \\
&
\end{tabular}

Notes: Bolded elements are statistically significantly different between the US and non-US samples; T-test significance $\mathrm{p}<.05 ; \mathrm{N}=559$ planners, US $=405$, non-US $=154$. 
barriers, facilitating practices, and engagement strategies. We also control for community size, the sector where the respondent works (public or not), and metro status. We expected that communities with more motivations, fewer barriers, more facilitating practices and strategies of engagement will have more LCA actions. We expect more LCA actions will lead to more LCA outcomes. All data are from the 2017 International Planner Engagement Survey. Model equations are shown below:

LCA actions $=f$ \{motivations, barriers, engagement strategies, facilitating practices, controls\}

LCA outcomes $=f\{$ LCA actions, motivations, barriers, engagement strategies, facilitating practices, controls\}

\subsection{Motivations}

The survey included yes-no questions on eleven motivations for planning LCA. We conducted factor analysis on the motivations, which differentiated them into three groups: local motivation, business motivation, and external opportunity or shock motivation (Table 2). The most common local motivations are: "growth in aging population" (28\%), "priority identified in a community planning process" (19\%), "policy opportunity" (16\%), and "local grassroots advocacy" (14\%). Business motivations include: "staff interest or expertise" (13\%), "opportunity to leverage a project already underway" (7\%), and "pressure from business leaders" (1\%). The external opportunity or shock motivations include: "national/regional policy mandates" (7\%), "new funding or programmatic opportunity" (7\%), and "an incident such as an older pedestrian fatality at a dangerous crosswalk" (3\%). The motivation, "pressure from local officials" (6\%), evenly loaded on local motivation and external opportunity or shocks. We expect communities ranking higher on motivations will engage in more LCA actions and achieve more LCA outcomes.

\subsection{Barriers}

Planners were asked to indicate the barriers limiting their planning for LCA. Respondents reported barriers in a "yes or no" question format (coded yes = 1 and no $=0$ ). Through factor analysis we found that barriers are grouped into four categories: resource barriers, traditional barriers, knowledge barriers, and political barriers (Table 3). Resource barriers include the most common barriers: "lack of financial resources" (24\%), and "lack of time" (19\%). Traditional barriers include: "not a high priority" (20\%), "political directives/mandate from elected officials" (12\%), and "narrow focus of work on technical issues" (12\%). Knowledge barriers include: "lack information on needs of all ages" (15\%), "lack knowledge or tools to plan for LCA" (15\%). The barriers, "not engaged with the people who work on these issues" (13\%), and "focus on traditional planning approaches" (22\%) loaded similarly on traditional barrier and knowledge barrier. Political barriers include: "ageist bias" (3\%), "gender bias" (1\%), "department policies" (5\%), and "workplace leaders are not supportive" (6\%). We note that political barriers are not reported by many respondents. We expected that communities facing more barriers will have fewer LCA actions or LCA outcomes.

\subsection{Facilitating Practices}

The survey measured seven practices facilitating planners' work on LCA (Table 4). Respondents were asked to select all the practices facilitating their work. The most common is support from colleagues (22\%). Compared to the US planners, a higher percentage of planners from

Table 2. Factor analysis of LCA motivations. Source: International Planner Engagement Survey (AARP, 2017).

\begin{tabular}{|c|c|c|c|}
\hline \multirow{2}{*}{$\begin{array}{l}\text { Motivations: Local governments' motivation in making planning LCA } \\
\text { a part of their practice (\% yes overall) }\end{array}$} & \multicolumn{3}{|c|}{ Factor Loadings } \\
\hline & Local & Business & External or shocks \\
\hline $\begin{array}{l}\text { Substantial growth in aging population and need to better serve this segment } \\
\text { of the population (28\%) }\end{array}$ & 0.76 & 0.08 & 0.21 \\
\hline Priority identified during a community planning process (19\%) & 0.8 & 0.13 & 0.01 \\
\hline $\begin{array}{l}\text { A policy window that presented an opportunity (e.g., comprehensive/ } \\
\text { transportation/pedestrian planning process) }(16 \%)\end{array}$ & 0.7 & 0.02 & 0.1 \\
\hline Local grassroots advocacy around an issue (14\%) & 0.65 & -0.21 & 0.23 \\
\hline Building on interest or expertise of staff (13\%) & 0.54 & 0.41 & 0.08 \\
\hline An opportunity to leverage a project or program already underway (7\%) & 0.43 & 0.34 & 0.29 \\
\hline Pressure from local officials (6\%) & 0.39 & -0.09 & 0.4 \\
\hline $\begin{array}{l}\text { Policy/ies (at national/regional/local/company level) that mandate this } \\
\text { perspective (7\%) }\end{array}$ & 0.21 & 0 & 0.63 \\
\hline An incident such as an older pedestrian fatality at a dangerous crosswalk (3\%) & 0.09 & -0.01 & 0.74 \\
\hline A new funding or programmatic opportunity (7\%) & 0.08 & 0.36 & 0.66 \\
\hline Pressure from business leaders (1\%) & 0.03 & 0.83 & 0.06 \\
\hline
\end{tabular}

Notes: Bold numbers show elements that primarily load on that factor. Factor loading after varimax rotation; $\mathrm{N}=559$ planners. 
Table 3. Factor analysis of LCA barriers. Source: International Planner Engagement Survey (AARP, 2017).

Barriers: catalysts/motivators for planners to participate in planning LCA? (\% yes overall)

Factor Loadings

Not a high priority (20\%)

Not engaged with the people who work on these issues (13\%)

Narrow focus of work on technical issues (12\%)

Political directives/mandate from elected officials (12\%)

Focus on traditional planning approaches (22\%)

Workplace leaders are not supportive (6\%)

Lack of information on needs of all age populations (15\%)

Lack of knowledge, skills, or tools to plan LCA (15\%)

Department policies (5\%)

Ageist bias (3\%)

Gender bias (1\%)

Lack of financial resources (24\%)

Lack of time (19\%)

\begin{tabular}{cccr}
\multicolumn{4}{c}{ Factor Loadings } \\
$\begin{array}{c}\text { Traditional } \\
\text { barrier }\end{array}$ & $\begin{array}{c}\text { Knowledge } \\
\text { barrier }\end{array}$ & $\begin{array}{c}\text { Political } \\
\text { barrier }\end{array}$ & $\begin{array}{r}\text { Resource } \\
\text { barrier }\end{array}$ \\
\hline $\mathbf{0 . 6 3}$ & 0.21 & 0.03 & 0.19 \\
$\mathbf{0 . 5 8}$ & $\mathbf{0 . 4 7}$ & -0.03 & -0.14 \\
$\mathbf{0 . 7 1}$ & 0.1 & 0.09 & 0.15 \\
$\mathbf{0 . 5 8}$ & -0.1 & 0.29 & 0.31 \\
$\mathbf{0 . 5}$ & $\mathbf{0 . 4 6}$ & 0.15 & 0.14 \\
$\mathbf{0 . 3 8}$ & 0.15 & $\mathbf{0 . 4 4}$ & 0.15 \\
0.06 & $\mathbf{0 . 8 3}$ & 0.1 & 0.17 \\
0.14 & $\mathbf{0 . 7 8}$ & 0.05 & 0.16 \\
0.18 & -0.04 & $\mathbf{0 . 7}$ & 0.08 \\
0.03 & 0.18 & $\mathbf{0 . 6 3}$ & 0.14 \\
0.01 & 0.11 & $\mathbf{0 . 8 1}$ & -0.03 \\
0.15 & 0.23 & 0.14 & $\mathbf{0 . 7 6}$ \\
0.08 & 0.11 & -0.03 & $\mathbf{0 . 8 3}$
\end{tabular}

Notes: Bold numbers show elements that primarily load on that factor; factor loading after varimax rotation; $\mathrm{N}=559$ planners.

Table 4. Facilitating practices and engagement strategies. Source: International Planner Engagement Survey (AARP, 2017).

Facilitating practices: Practices facilitating planners' work on LCA (\% yes overall)

- Colleagues support an all ages approach to planning (22\%)

- Workplace policies encourage an all ages approach to planning (14\%)

- Periodic focus group interactions with aging population (11\%)

- Special project funding for LCA (7\%)

- Elected officials holding meetings with LCA focus (5\%)

- Client prioritizes LCA (4\%)

- Release time to work on LCA (3\%)

\begin{tabular}{rr} 
US & Non-US \\
\hline $21 \%$ & $22 \%$ \\
$11 \%$ & $22 \%$ \\
$9 \%$ & $18 \%$ \\
$5 \%$ & $12 \%$ \\
$4 \%$ & $7 \%$ \\
$4 \%$ & $4 \%$ \\
$1 \%$ & $7 \%$ \\
\hline
\end{tabular}

Engagement strategies: Strategies most effective to engage planners to plan LCA (\% yes overall)

- Engaging elected officials, legislators to talk about LCA (32\%)

- Hosting training or seminars on planning LCA (27\%)

- Hosting participatory meetings with planners and community residents on LCA (25\%)

- Providing written information on changing demographics and related issues (20\%)

- Undertaking tactical urbanism activities (20\%)

- Launching public campaigns or advertisements about LCA (18\%)

- Participating in a community-wide LCA initiative (17\%)

US Non-US

- Inviting planners to speak at community meetings on LCA (16\%)

\begin{tabular}{ll}
\hline $\mathbf{3 5 \%}$ & $\mathbf{2 5 \%}$ \\
$29 \%$ & $23 \%$ \\
$25 \%$ & $24 \%$ \\
$21 \%$ & $18 \%$ \\
$20 \%$ & $22 \%$ \\
$19 \%$ & $18 \%$ \\
$15 \%$ & $21 \%$ \\
$16 \%$ & $18 \%$ \\
\hline
\end{tabular}

Notes: Bolded elements are statistically significantly different between the US and non-US samples; T-test significance $\mathrm{p}<.05 ; \mathrm{N}=559$ planners, US $=405$, non-US $=154$.

other countries reported that workplace policy (non-US: $22 \%$, US: $11 \%)$, focus group interactions with the aging population (non-US: $18 \%$, US: $9 \%$ ), project funding (nonUS: $12 \%$, US: $5 \%$ ), and time (non-US: $7 \%$, US: $1 \%$ ) can improve their work on LCA. Other facilitating practices show no difference between US and non-US respondents, including elected official holding meetings with LCA focus (5\%) and client prioritizes LCA (4\%). We added up the total number of selected elements to create the facilitating practices indicator (alpha: 0.7). We hypothesize more facilitating practices are related to more LCA actions and LCA outcomes.

\subsection{Engagement Strategies}

Planners were asked about the effectiveness of eight strategies encouraging them to engage in LCA (Table 4). The most effective strategy is "engaging elected officials, legislators to talk about LCA" (32\%), which was especially noted by the US planners (US: $35 \%$, non-US: $25 \%$ ). A quarter of respondents reported that trainings, seminars, and participatory meetings are effective to get planners to plan for LCA. A fifth of planers indicated that providing written information, undertaking urbanism activities, and advertisement about LCA are effective strategies. More Non-US planners reported that participating 
in LCA initiatives and inviting planners to talk about LCA are effective strategies (participation: US: 15\%, Non-US: $21 \%$; invitation of planners: US: $16 \%$, Non-US: $18 \%$ ). We summed the number of selected strategies to create the indicator (alpha: 0.8). We hypothesize that communities with more strategies of engagement will have more LCA actions and outcomes.

We are interested in differentiating the factors driving LCA actions and outcomes in the US sample and nonUS sample respectively (Table 5). Compared to non-US planners, US planners reported fewer facilitating practices, fewer external motivations and fewer LCA actions. However, US planners also reported fewer political barriers than the non-US planners, though political barriers were low overall. We also controlled the model for population size, metro status and whether the planner worked for the public or private sector. Compared to the US sample, the non-US sample included larger places and fewer suburbs.

\section{Results}

We ran two ordinary least square regressions to understand the differences in factors that explain the level of LCA actions and outcomes. Regression results are shown in Table 6. To assess the impact of variables on a standard scale, we report standardized coefficients. As expected, we found that more local governments actions to advance LCA are related to a higher level of outcomes (incorporating the LCA approach into planning practices). This is true for both the US and non-US sample.

For both the US and the non-US sample, facilitating practices (including policy support, funding and older adult engagement) play an important role in both LCA ac- tions and outcomes. Indeed, facilitating practices have the largest impact of any model variable in the LCA outcomes model. The engagement strategies (including engaging officials to talk about LCA, hosting meeting and seminars) also shows high impact on LCA outcomes. If a community uses more strategies for planners' engagement in planning LCA, then the community is more likely to incorporate the LCA approach into its planning practices. Our model results confirm the role of engagement strategies in building LCA (Fitzgerald \& Caro, 2017; Warner, Homsy, \& Morken, 2017; Warner, Xu, \& Morken, 2017; WHO, 2007).

Local motivations are the main factor driving local governments' LCA actions in both the US and non-US samples. Motivations have the highest effect of any model variable. US local governments' LCA actions are also driven by external motivations (though with less than half the impact of local motivations), but external motivation is not a driver for the non-US sample. Similarly, business motivation has a positive effect on LCA outcomes in the US model, but not in the non-US sample. This may reflect the greater emphasis on market leadership rather than public policy leadership in the US.

Regarding barriers, while knowledge barriers slow LCA action in the US sample, most of the barriers have no effect. In the LCA outcomes models, while both traditional barriers (which includes traditional planning approaches) and resource barriers are significant, planners report more LCA outcomes despite higher barriers in both samples. This is promising news indeed. A lack of financial resources or time does not appear to stop the incorporation of an all age lens in planning. Our model results show that LCA approaches are complementary to traditional planning.

Table 5. LCA model variables: US/non-US comparison. Source: International Planner Engagement Survey (AARP, 2017).

\begin{tabular}{|c|c|c|c|}
\hline & $\begin{array}{l}\text { US sample } \\
\mathrm{N}=405\end{array}$ & $\begin{array}{c}\text { Non-US sample } \\
\qquad N=154\end{array}$ & $\begin{array}{c}\mathrm{T} \\
\text { Test }\end{array}$ \\
\hline \multicolumn{4}{|l|}{ Dependent variables } \\
\hline Outcomes (number of elements $=11$, scale $0-5$ ) & 18.34 & 17.79 & 0.31 \\
\hline Actions (number of elements $=8$, yes $=1$ ) & 1.4765 & 1.9675 & $-2.51^{*}$ \\
\hline \multicolumn{4}{|l|}{ Independent variables } \\
\hline Local motivation (factor score) & 0.0149 & -0.0391 & 0.57 \\
\hline External motivation (factor score) & -0.0525 & 0.1380 & $-2.02 *$ \\
\hline Business motivation (factor score) & -0.0407 & 0.1071 & -1.56 \\
\hline Tradition barrier (factor score) & 0.0011 & -0.0029 & 0.04 \\
\hline Knowledge barrier (factor score) & -0.0030 & 0.0078 & -0.11 \\
\hline Politics barrier (factor score) & -0.0747 & 0.1966 & $-2.88^{*}$ \\
\hline Resource barrier (factor score) & -0.0168 & 0.0441 & -0.64 \\
\hline Engagement Strategies (number of elements $=8$, yes $=1$ ) & 1.8420 & 1.7143 & 0.60 \\
\hline Facilitating practices (number of elements $=7$, yes $=1$ ) & 0.5975 & 0.9481 & $-3.06 *$ \\
\hline Population size (scale $1=$ less than 5,000 ...to $6=$ I million or more) & 3.5333 & 4.0130 & $-3.24 *$ \\
\hline Public sector (yes $=1$ ) & 0.4173 & 0.3506 & 1.44 \\
\hline Suburb (yes = 1) & 0.3654 & 0.2208 & $3.29 *$ \\
\hline Rural (yes = 1) & 0.2272 & 0.2078 & 0.49 \\
\hline
\end{tabular}

Notes: $\mathrm{N}=559{ }^{*}$ significant at $\mathrm{p}<.05$. 
Table 6. OLS regression results: LCA actions and outcomes. Source: International Planner Engagement Survey (AARP, 2017).

\begin{tabular}{|c|c|c|c|c|}
\hline & \multicolumn{2}{|c|}{ US sample } & \multicolumn{2}{|c|}{ Non-US sample } \\
\hline & LCA Actions & LCA Outcomes & LCA Actions & LCA Outcomes \\
\hline LCA actions & & $0.14^{* *}$ & & $0.12^{*}$ \\
\hline Local motivation & $0.40 * *$ & 0.05 & $0.35^{* *}$ & 0.03 \\
\hline External motivation & $0.16^{* *}$ & -0.01 & -0.01 & -0.09 \\
\hline Business motivation & -0.01 & $0.08^{*}$ & 0.06 & -0.01 \\
\hline Tradition barrier & -0.03 & $0.13^{* *}$ & 0.05 & $0.14^{* *}$ \\
\hline Knowledge barrier & $-0.10^{*}$ & 0.05 & -0.10 & 0.08 \\
\hline Politics barrier & 0.02 & -0.01 & -0.04 & -0.05 \\
\hline Resource barrier & -0.03 & $0.13^{* *}$ & 0.00 & $0.14^{* *}$ \\
\hline Engagement strategies & 0.03 & $0.22 * *$ & -0.08 & $0.21 * *$ \\
\hline Facilitating practices & $0.31 * *$ & $0.23^{* *}$ & $0.41^{* *}$ & $0.27 * *$ \\
\hline Community size & 0.08 & -0.03 & 0.05 & 0.05 \\
\hline Public sector & 0.09 & $0.26 * *$ & $0.21^{* *}$ & $0.37 * *$ \\
\hline Suburb & $-0.10 * *$ & $-0.07^{*}$ & 0.02 & -0.02 \\
\hline Rural & $-0.10^{*}$ & -0.02 & 0.08 & -0.09 \\
\hline $\mathrm{N}$ & 405 & 405 & 154 & 154 \\
\hline R-square & 0.51 & 0.67 & 0.55 & 0.79 \\
\hline Adj. R-square & 0.50 & 0.66 & 0.51 & 0.77 \\
\hline
\end{tabular}

Notes: Standard coefficients, ${ }^{* *} \mathrm{p}<.01,{ }^{*} \mathrm{p}<.05 ;$ multicollinearity test shows that mean VIF of each model is less than $2 ; \mathrm{N}=559$.

Planners working in the public sector report higher LCA outcomes, compared to planners working in the private sector. Public sector planners are also more likely to report their local governments take more LCA actions in the non-US sample.

Suburbs and rural communities report fewer actions in the US sample, and suburbs report lower outcomes. Metro status is not significant in the non-US sample, but this could be due to a lower percentage of suburban and rural respondents in the non-US sample.

\section{Discussion}

Our models have shown that local government LCA actions lead to more outcomes incorporating an LCA approach. Facilitating practices help planners increase LCA actions and outcomes. Engagement strategies are key to LCA outcomes as well. These models confirm the importance of engagement and collaboration among planners and their communities around the world (Greenfield et al., 2015; Plouffe \& Kalache, 2011). See Figure 1.

We expected a positive relation between motivation and LCA action and outcomes. While we found local moti- vation is key to LCA action, motivations are not significant on LCA outcomes. This is because actions, facilitating practices and engagement, are what drive LCA outcomes. Only the business motivation had a direct impact on outcomes, and only in the US sample. However, we ran separate models on Canada, Europe, and Australia, and also found business motivation is positively related to the incorporation of LCA in Australia. Survey respondents were invited to submit case studies. A planner from Melville, Australia, reported how the business community can promote LCA outcomes. The second largest shopping center in the State of Victoria is undergoing a major remodeling driven by the increasing needs of older adult customers (particularly those with dementia). The City of Melbourne created an Access Advisory Group comprised of people with a range of ages and disabilities to consult on all large projects and events. The advisory group helps inform age/dementia-friendly design features, which the business community is using in redesign. This shows the power of engagement in facilitating practices to promote LCA outcomes.

Barriers do not hold LCA back. Communities facing traditional planning barriers and resource barriers report

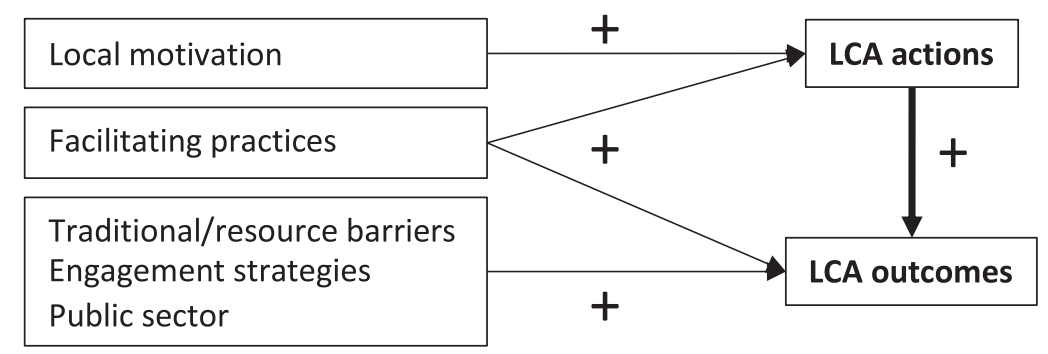

Figure 1. Summary of main findings. Note: + denotes a positive relation. 
higher levels of LCA outcomes. Resource barriers are a challenge in developing LCA (Greenfield et al., 2015; Lui et al., 2009), but our models show incorporating all age lens into planning practices could be a promising way for communities facing traditional resource barriers (Green, 2013). We also use pair-wise comparison to examine the relation between engagement strategies and barriers, and find that engagement strategies are positively related to all barriers. The results suggest that barriers may also be overcome by engagement strategies.

\subsection{Rural/Suburban Differences in the US}

We conducted a deeper analysis of the US sample, where rural and suburban respondents were dominant, and compared this sample to US communities as a whole using the AARP 2018 livability indicators, which measure seven domains of age-friendly communities ${ }^{2}$ based on WHO's (2007) framework. We conducted T-tests between US survey respondents and all US places and found that the LCA survey respondents are from places with better livability in the environment, health, neighborhood, transportation, and opportunity, but no difference in engagement and housing. Our suburban survey respondents have significantly lower scores in the categories of the neighborhood, transportation, and housing than the US as a whole. These are built environment features which make it difficult for suburbs to meet the needs of the aging population.

To understand what drives the lag in LCA actions and outcomes in US suburbs and rural communities, we reran our LCA Action and Outcome models separately for US suburban and rural respondents. We found that political and knowledge barriers impede LCA in rural communities, and external motivation does not promote LCA action in suburbs. But local motivation, facilitating practices and community engagement strategies were important in all models (Table 7). These results suggest that it is the social layer that matters most. An inclusive environment, created by engagement and facilitating practices, is key to helping US suburbs and rural areas improve LCA actions and outcomes. The emphasis on new urbanist physical design principles does not work for many suburban and rural areas. Our model results suggest that to overcome knowledge barriers, we need to develop agefriendly strategies specifically designed for suburban and rural areas. Attention to community engagement and facilitating practices is key to identifying new approaches.

\subsection{Study Limitations}

Our study has several limitations. First, some of the wording of survey questions on facilitating practices and engagement strategies is similar, and this could make differentiation of facilitating practices and engagement strategies difficult. However, we ran factor analysis to examine the correlation among questions and found that all the elements in engagement strategies are grouped separately from elements in facilitating practices. Thus, we keep them as two separate variables. Second, the surveys were sent to planners around the world. Most of the planners are from the public sector (72\%), 19\% from the

Table 7. Urban/suburban/rural comparison of model results: US subsample. Source: International Planner Engagement Survey (AARP, 2017).

\begin{tabular}{|c|c|c|c|c|c|c|}
\hline & \multicolumn{2}{|c|}{ Urban } & \multicolumn{2}{|c|}{ Suburban } & \multicolumn{2}{|c|}{ Rural } \\
\hline & $\begin{array}{c}\text { LCA } \\
\text { Actions }\end{array}$ & $\begin{array}{c}\text { LCA } \\
\text { Outcomes }\end{array}$ & $\begin{array}{c}\text { LCA } \\
\text { Actions }\end{array}$ & $\begin{array}{c}\text { LCA } \\
\text { Outcomes }\end{array}$ & $\begin{array}{c}\text { LCA } \\
\text { Actions }\end{array}$ & $\begin{array}{c}\text { LCA } \\
\text { Outcomes }\end{array}$ \\
\hline LCA Actions & & $0.17^{*}$ & & -0.06 & & 0.28 \\
\hline Local motivation & $0.45^{* *}$ & 0.05 & $0.34 * *$ & 0.05 & $0.32 * *$ & 0.07 \\
\hline External motivation & $0.25^{* *}$ & 0.04 & -0.04 & -0.10 & $0.39 * *$ & -0.01 \\
\hline Business motivation & 0.05 & -0.02 & 0.01 & 0.12 & 0.09 & 0.06 \\
\hline Tradition barrier & -0.10 & 0.08 & -0.05 & $0.19 * *$ & -0.03 & 0.06 \\
\hline Knowledge barrier & -0.11 & 0.10 & -0.08 & 0.03 & $-0.23 *$ & 0.06 \\
\hline Politics barrier & 0.01 & -0.01 & -0.03 & 0.05 & -0.01 & $-0.19 * *$ \\
\hline Resource barrier & 0.05 & $0.17^{*}$ & -0.05 & $0.17 * *$ & -0.12 & 0.06 \\
\hline Engagement Strategies & 0.10 & $0.17^{*}$ & 0.01 & $0.21^{* *}$ & 0.14 & $0.31^{*}$ \\
\hline Facilitating Practices & 0.11 & 0.13 & $0.41 * *$ & $0.37 * *$ & $0.34 * *$ & 0.14 \\
\hline Community size & 0.09 & -0.09 & 0.05 & 0.05 & -0.03 & -0.01 \\
\hline Public sector & 0.06 & $0.27^{* *}$ & 0.16 & $0.28 * *$ & 0.15 & $0.26^{*}$ \\
\hline $\mathrm{N}$ & 148 & 148 & 135 & 135 & 74 & 74 \\
\hline R-square & 0.48 & 0.65 & 0.56 & 0.74 & 0.77 & 0.72 \\
\hline Adj. R-square & 0.43 & 0.62 & 0.52 & 0.71 & 0.73 & 0.66 \\
\hline
\end{tabular}

Notes: standard coefficients, ${ }^{* *} \mathrm{p}<.01, * \mathrm{p}<.05$.

\footnotetext{
$\overline{2}$ See livabilityindex.aarp.org
} 
private sector, and $8 \%$ from the nongovernment or nonprofit sector. The understanding of LCA may vary across sectors, which could cause estimation bias. Third, although the survey is conducted at an international scale, more than $70 \%$ of respondents are from the US. We group all the non-US respondents together to ensure sufficient sample size for regression analysis. However, the non-US countries sample includes seven different countries, which may be differentiated by planning practices. We separated the non-US sample into non-US developed countries (Canada, Europe, and Australia/New Zealand) and non-US developing countries (Latin America, Asia, Africa, and the Middle East). We conducted t tests for differences in means and found that only external motivation differentiates the two subsamples. We also ran the regression model only using non-US developed countries. Results show that engagement strategies are not related to the LCA outcomes, and the public sector is not related to LCA actions. Other results are the same as the overall non-US sample results. Thus, we conclude that, due to small sample size, our non-US sample cannot capture the differences between countries.

\section{Conclusion}

In this study, we analyzed the 2017 International Planner Engagement Survey on LCA to see if we could differentiate motivations, barriers and facilitating practices driving local government actions and outcomes on LCA. While US respondents reported lower levels of LCA action and engagement, facilitating practices and engagement strategies were key to higher levels of LCA outcomes for all respondents. By creating a supportive work environment and engaging stakeholders, planners can increase actions to promote LCA. Local motivation is keythis includes knowledge and expertise as well as advocacy and political pressure. Barriers do not hold back LCA incorporation, except in US rural communities. These results suggest a promising way forward for building livable communities for all ages. Even in communities facing limited resources and focusing on traditional planning approaches, community engagement and facilitating strategies offer a means to promote a livability for all ages approach. It is the social innovations that move us forward.

\section{Acknowledgments}

We would like to thank the APA Divisions Council for funding support of the international survey analysis. We also would like to thank additional members of the survey research team, Tim van Epp of the APA International Division, Michael Amabile and Greyson Clark of Arup, and Brad Gudzinas, Rodney Harrell and Cheryl Lampkin of AARP for their assistance with this project. This work is supported by the USDA National Institute of Food and Agriculture, Agricultural and Food Research Initiative Competitive Program, Agriculture Economics and Rural Communities, grant \#2018-07005.

\section{Conflict of Interests}

The authors declare no conflict of interests.

\section{References}

AARP. (2018). 2018 Home and community preferences: A national survey of adults age 18-plus. AARTP. Retrieved from www.aarp.org/livablesurvey 2018

AARP. (2017). International planner engagement survey. Washington, DC: AARP.

Andriola, V., \& Muccitelli, S. (2017). Framing a multigenerational approach to planning. The Italian context. iQuaderni di Urbanistica Tre, 2017(14). Retrieved from www.urbanisticatre.uniroma3.it/dipsu/?page_ id $=5459$

APA. (2014). Aging in community policy guide. Chicago, IL: American Planning Association.

Ball, M. S. (2004). Aging in place: A toolkit for local governments. Atlanta, GA: Atlanta Regional Commission.

Brown, D. L., Glasgow, N., Kulcsar, L. J., Sanders, S., \& Thiede, B. C. (2018). The multi-scalar organization of aging-related services in US rural places. Journal of Rural Studies. https://doi.org/10.1016/j.jrurstud. 2018.09.010

Buffel, T., \& Phillipson, C. (2016). Can global cities be 'agefriendly cities'? Urban development and ageing populations. Cities, 55, 94-100. https://doi.org/10.1016/ j.cities.2016.03.016

Choi, M., \& Warner, M. E. (2015). Collaboration: The key to building communities for all generations. In The municipal yearbook 2015 (pp. 27-39). Washington, DC: International City County Management Association. Retrieved from http://cms.mildredwarner.org/ $\mathrm{p} / 216$

Duany, A., \& Plater-Zyberk, E. (2009). Lifelong communities: A regional guide to growth and longevity. Atlanta, GA: Atlanta Regional Commission.

Emlet, C. A., \& Moceri, J. T. (2012). The importance of social connectedness in building age-friendly communities. Journal of Aging Research. http://dx.doi.org/ 10.1155/2012/173247

Farber, N., Shinkle, D., Lynott, J., Fox-Grage, W., \& Harrell, R. (2011). Aging in place: A state survey of livability policies and practices. Washington, DC: National Conference of State Legislatures and AARP Public Policy Institute. Retrieved from www.aarp.org/homegarden/livable-communities/info-11-2011/ solutions-forum-aging-in-place.html

Firestone, S. K., Keyes, L., \& Greenhouse, E. (2018). Planners and aging professionals collaborate for livable communities. Working with Older People, 22(1), 20-29.

Fitzgerald, K. G., \& Caro, F. G. (2014). An overview of age-friendly cities and communities around the world. Journal of Aging \& Social Policy, 26(1/2), 1-18. https://doi.org/10.1080/08959420.2014.860786

Fitzgerald, K. G., \& Caro, F. G. (2017). International 
perspectives on age-friendly cities. New York, NY: Routledge.

Gallagher, E., Menec, D. V., \& Keefe, D. J. (2006). Agefriendly rural and remote communities: $A$ guide. Toronto: Federal, Provincial and Territorial Ministers Responsible for Seniors.

Glasgow, N., \& Brown, D. L. (2012). Rural ageing in the United States: Trends and contexts. Journal of Rural Studies, 28(4), 422-431.

Glicksman, A., Clark, K., Kleban, M. H., Ring, L., \& Hoffman, C. (2014). Building an integrated research/ policy planning age-friendly agenda. Journal of Aging \& Social Policy, 26(1/2), 131-146. https://doi.org/ 10.1080/08959420.2014.854142

Green, G. (2013). Age-friendly cities of Europe. Journal of Urban Health, 90(1), 116-128. https://doi.org/10. 1007/s11524-012-9765-8

Greenfield, E. A., Oberlink, M., Scharlach, A. E., Neal, M. B., \& Stafford, P. B. (2015). Age-friendly community initiatives: Conceptual issues and key questions. Gerontologist, 55(2), 191-198. https://doi.org/ 10.1093/geront/gnv005

Hanlon, B. (2008). The decline of older, inner suburbs in metropolitan America. Housing Policy Debate, 19(3), 423-456. https://doi.org/10.1080/10511482. 2008.9521642

He, W., Goodkind, D., \& Kowal, P. R. (2016). An aging world: 2015. Washington, DC: United States Census Bureau.

Howe, D. (2012). Aging as the foundation for livable communities. In F. Wagner \& R. Caves (Eds.), Community livability: Issues and approaches to sustaining the well-being of people and communities (pp. 97-114, 1st ed.). New York, NY: Routledge.

Joint Center for Housing Studies. (2018). Housing America's older adults 2018. Cambridge, MA: Joint Center for Housing Studies. Retrieved from www.jchs. harvard.edu/housing-americas-older-adults-2018

Kendig, H., Elias, A.-M., Matwijiw, P., \& Anstey, K. (2014). Developing age-friendly cities and communities in Australia. Journal of Aging and Health, 26(8), 1390-1414.

Kochera, A., Straight, A., \& Guterbock, T. (2005). 50.05: A report to the Nation on livable communities. Creating environments for successful aging. Washington, DC: AARP.

Lee, J. K., Hong, S. H., \& Park, Y. M. (2017). Predictable surprise: The spatial and social morphology of aging suburbs in the US metropolitan areas. Sustainability, 9(3). https://doi.org/10.3390/su9030458

Lehning, A. J. (2012). City governments and aging in place: Community design, transportation, and housing innovation adoption. Gerontologist, 52(3), 345-356. https://doi.org/10.1093/geront/gnr089

Lehning, A. J. (2014). Local and regional governments and age-friendly communities: A case study of the San Francisco Bay Area. Journal of Aging \& Social Policy, 26(1/2), 102-116. https://doi.org/10.1080/
08959420.2014 .854140

Lehning, A. J., \& Greenfield, E. A. (2017). Research on age-friendly community initiatives: Taking stock and moving forward. Journal of Housing for the Elderly, 31(2), 178-192. https://doi.org/10.1080/02763893. 2017.1309937

Lui, C. W., Everingham, J. A., Warburton, J., Cuthill, M., \& Bartlett, H. (2009). What makes a community agefriendly: A review of international literature. Australasian Journal on Ageing, 28(3), 116-121. https:// doi.org/10.1111/j.1741-6612.2009.00355.x

Micklow, A. C., \& Warner, M. E. (2014). Not your mother's suburb: Remaking communities for a more diverse population. Urban Lawyer, 46(4), 729-751.

Morken, L., \& Warner, M. (2012). Planning for the aging population: Rural responses to the challenge (Issue Brief). Washington and Ithaca: National Association of Area Agencies on Aging and Cornell University. Retrieved from cms.mildredwarner.org/p/146

Novek, S., \& Menec, V. H. (2014). Older adults' perceptions of age-friendly communities in Canada: A photovoice study. Ageing \& Society, 34(6), 1052-1072.

Plouffe, L. A., \& Kalache, A. (2011). Making communities age friendly: State and municipal initiatives in Canada and other countries. Gaceta Sanitaria, 25, 131-137. https://doi.org/10.1016/j.gaceta.2011.11.001

Pratt, E. E., \& Warner, M. E. (2018). Imagining the "Good place": Public services and family strategies in rural Ecuador. Rural Sociology. https://doi.org/10.1111/ ruso.12231

Sancar, F. H., \& Severcan, Y. C. (2010). Children's places: Rural-urban comparisons using participatory photography in the Bodrum peninsula, Turkey. Journal of Urban Design, 15(3), 293-324.

Severcan, Y. C. (2015a). Planning for the unexpected: Barriers to young people's participation in planning in disadvantaged communities. International Planning Studies, 20(3), 251-269.

Severcan, Y. C. (2015b). The effect of childen's participation in planning and design activities on their place attachment. Journal of Architectural and Planning Research, 32(4), 271-293.

Thiede, B. C., Brown, D. L., Sanders, S. R., Glasgow, N., \& Kulcsar, L. J. (2017). A demographic deficit? Local population aging and access to services in rural America, 1990-2010. Rural Sociology, 82(1), 44-74.

UNICEF. (2004). Building child friendly cities: A framework for action. New York, NY: UNICEF. Retrieved from unicef-irc.org/publications/416

UNICEF. (2018). Shaping urbanization for children: A handbook on child-responsive urban planning. New York, NY: UNICEF. Retrieved from www.unicef.org/ publications/index_103349.html

US Census Bureau. (2017). American Community survey, 2011-2016. Washington, DC: US Department of Commerce.

Warner, M. E. (2006). Market-based governance and the challenge for rural governments: US trends. Social 
Policy \& Administration, 40(6), 612-631.

Warner, M. E. (2017). Multigenerational planning: Theory and practice. iQuaderni di Urbanistica Tre, 2017(14). Retrieved from www.urbanisticatre. uniroma3.it/dipsu/wp-content/uploads/2018/01/ u3_quaderni_14_warner.pdf

Warner, M. E., \& Homsy, G. C. (2017). Multi-generational Planning: Integrating the needs of elders and children. In F. Caro \& K. Fitzgerald (Eds.), International perspectives on age friendly cities (pp. 227-240). New York, NY: Routledge.

Warner, M. E., Homsy, G. C., \& Morken, L. J. (2017). Planning for aging in place: Stimulating a market and government response. Journal of Planning Education and Research, 37(1), 29-42. https://doi.org/ 10.1177/0739456X16642824

Warner, M. E., \& Morken, L. (2013). Building child and age friendly communities in tight fiscal times. In The 2013 municipal yearbook (pp. 47-56). Washington, DC: International City County Management Association.

Warner, M. E., Xu, Y., \& Morken, L. (2017). What explains differences in availability of community healthrelated services for seniors in the United States? Journal of Aging and Health, 29(7), 1160-1181. https:// doi.org/10.1177/0898264316654675

Warner, M. E., \& Zhang, X. (2019). Planning communi- ties for all ages. Journal of Planning Education and Research. https://doi.org/10.1177/0739456X19828 058

Winick, B., \& Jaffe, M. (2015). Planning aging-supportive communities. APA Planning Association. Retrived from www.planning.org/publications/report/90269 02

World Health Organization. (2002). Active ageing: A policy framework. Geneva: World Health Organization Press. Retrieved from whqlibdoc.who.int/hq/2002/ WHO_NMH_NPH_02.8.pdf

World Health Organization. (2007). Global age-friendly cities: A guide. Geneva: World Health Organization Press.

Winters, M., Voss, C., Ashe, M. C., Gutteridge, K., McKay, H., \& Sims-Gould, J. (2015). Where do they go and how do they get there? Older adults' travel behaviour in a highly walkable environment. Social Science \& Medicine, 133, 304-312. https://doi.org/10.1016/j. socscimed.2014.07.006

Young, D., \& Keil, R. (2014). Locating the urban inbetween: Tracking the urban politics of infrastructure in Toronto. International Journal of Urban and Regional Research, 38(5), 1589-1608. https://doi.org/ 10.1111/1468-2427.12146

\section{About the Authors}

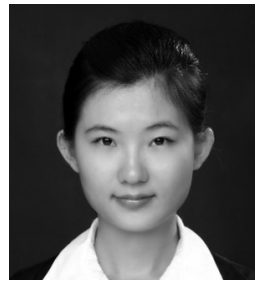

Xue Zhang is a PhD candidate in Regional Science at Cornell University. She is interested in age-friendly community development from an international prescriptive, sustainable development, equity, public health, and spatial modeling. Her research also explores the relation between demographic transition, economic development structure, and regional development disparities. She pays attention to the linkage between people's mobility, rural development and community development policy. Orchid address: 0000-0002-0109-338X

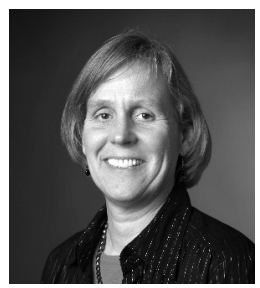

Mildred E. Warner is a Professor in the Department of City and Regional Planning at Cornell University, where her work focuses primarily on local government service delivery, economic development, environmental sustainability and multigenerational planning. Dr. Warner's research explores the impact of privatization and fiscal decentralization on local government and the role of human services as social infrastructure for economic development. She gives special attention to the needs of children, families and older adults and how local governments can respond. Orchid address: 0000-0002-5786-4235

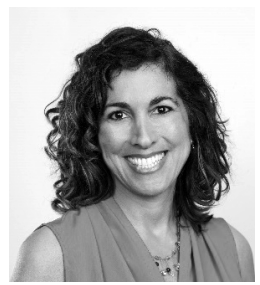

Stephanie Firestone is a Senior Strategic Policy Advisor with AARP International, where she focuses on global urban aging. Stephanie advances livable communities for people of all ages and abilities, by building a knowledge base around planning for aging populations, fostering collaboration between planners, aging professionals and other sectors, and infusing aging considerations into local government plans and policies. Stephanie holds a Master of Urban Planning degree from the University of Virginia. 